\title{
Synthesis and evaluation of an imidazo-benzocrown ether functionalised amino acid as a new fluorimetric chemosensor for metal ion detection
}

\author{
Rosa M. F. Batista, M. Manuela M. Raposo and Susana P. G. Costa \\ Centre of Chemistry, University of Minho, Campus of Gualtar, 4710-057 Braga, Portugal \\ mfox@quimica.uminho.pt
}

\begin{abstract}
A new unnatural phenylalanine derivative bearing benzimidazole and crown ether as coordinating/reporting units was synthesized, and its evaluation as colorimetric/fluorimetric chemosensor was carried out in acetonitrile solution. Compound $\mathbf{3}$ was tested for metal ion detection (such as $\mathrm{Ca}^{2+}, \mathrm{Cd}^{2+}, \mathrm{Co}^{2+}, \mathrm{Cr}^{3+}, \mathrm{Cu}^{2+}, \mathrm{Fe}^{2+}, \mathrm{Fe}^{3+}, \mathrm{Hg}^{2+}, \mathrm{Na}^{+}$, $\mathrm{Ni}^{2+}, \mathrm{Pd}^{2+}$ and $\left.\mathrm{Zn}^{2+}\right)$. The sensory properties and signaling mode, as seen by spectrofluorimetric titrations, showed that amino acid derivative $\mathbf{3}$ is a fluorimetric chemosensor, being highly sensitive for $\mathrm{Cu}^{2+}, \mathrm{Hg}^{2+}$ and $\mathrm{Pd}^{2+}$. The metal cation sensing properties displayed by compound $\mathbf{3}$ showed that it is a promising candidate for sensory applications.
\end{abstract}

Keywords: Phenylalanine; Imidazo-benzocrown ether; Fluorescence; Metal ion detection. 


\section{Introduction}

The field of fluorescent chemosensors has grown in recent years due to their importance in applications such as in material sciences, biomedical analysis, environmental sciences and analytical chemistry [1].

The design of heteroditopic chemosensors that contain two different binding sites for targeting substances over large concentration ranges and capable of analysing multiple analytes simultaneously is a new and emerging topical field of supramolecular chemistry [2]. Among supramolecular host molecules, crown ethers occupy a special position due to their wide use in the design of new chemosensors based on their unique ability to combine with the cations of alkali metals, with very high selectivity and accessibility. In addition to alkali metals, crown ethers are also effective complexing reagents for the cations of alkali-earth metals, and when nitrogen and sulfur atoms are inserted into their structure they become sensitive to transition metal ions [3].

Additionally, the introduction of an imidazole in the phenylalanine skeleton was expected to increase the overall fluorescence of the resulting amino acid derivative.

Having these facts in mind, and following our research interests that include the synthesis and evaluation of fluorimetric chemosensors for anions and cations based on heterocycles and amino acids [4], a new imidazo-benzocrown ether functionalised amino acid $\mathbf{3}$ was synthesized and its evaluation as a fluorescent chemosensor is now reported.

\section{Experimental}

\subsection{General procedure for the synthesis of benzimidazolyl phenylalanine 3}

A solution of $\mathrm{N}$-t-butyloxycarbonyl-4-formyl-L-phenylalanine methyl ester 1 (1 equiv) and 4amino-5-nitrobenzo-18-crown-6 2 (1 equiv) in absolute ethanol $(3 \mathrm{~mL})$ was treated with $\mathrm{Na}_{2} \mathrm{~S}_{2} \mathrm{O}_{4}$ (3 equiv), dissolved in a small volume of water, and heated at $80{ }^{\circ} \mathrm{C}$ with stirring for $15 \mathrm{~h}$. The mixture was poured into water $(20 \mathrm{~mL})$ and extracted with ethyl acetate $(3 \times 50$ $\mathrm{mL})$. The organic layer was dried with magnesium sulphate and evaporated under reduced pressure to give the crude benzimidazolyl phenylalanine $\mathbf{3}$ which was submitted to silica gel column chromatography using mixtures of dichloromethane and $n$-hexane of increasing polarity as eluent. The fractions containing the purified product were collected and evaporated under vacuum. 
Benzimidazolyl phenylalanine methyl ester (3)

Starting from phenylalanine derivative $1\left(0.34 \mathrm{~g}, 0.11 \times 10^{-3} \mathrm{~mol}\right)$ and benzocrown ether derivative $2\left(0.035 \mathrm{~g}, 0.11 \times 10^{-3} \mathrm{~mol}\right)$, compound 3 was obtained as a yellow oil $(0.044 \mathrm{~g}$, 70\%); ${ }^{1} \mathrm{H}$ NMR (400 MHz, $\left.\mathrm{CDCl}_{3}\right): \delta=1.42\left(\mathrm{~s}, 9 \mathrm{H}, \mathrm{C}\left(\mathrm{CH}_{3}\right)_{3}\right), 2.83-2.88$ 3.06-3.10 (m, $1 \mathrm{H}$, $\left.\beta-\mathrm{CH}_{2}\right), 3.68-3.98\left(\mathrm{~m}, 19 \mathrm{H}, 8 \times \mathrm{CH}_{2}\right.$ crown and $\left.\mathrm{OCH}_{3}\right), 4.55-4.57(\mathrm{~m}, 1 \mathrm{H}, \alpha-\mathrm{H}), 5.30$ (d, J 7.2 Hz, 1H, NH Boc), 7.04 (s, 1H, H4' and H7'), 7.19 (d, J 7.6 Hz, 2H, H2 and H6), 8.15 (d, J 7.2 $\mathrm{Hz}, 2 \mathrm{H}, \mathrm{H} 3$ and H5); ${ }^{13} \mathrm{C} \mathrm{NMR}\left(100.6 \mathrm{MHz}, \mathrm{CDCl}_{3}\right): \delta=28.32\left(\mathrm{C}_{\left.\left(\mathrm{CH}_{3}\right)_{3}\right),} 38.08\left(\beta-\mathrm{CH}_{2}\right)\right.$, $51.74\left(\mathrm{CH}_{2}\right.$ crown), $52.35\left(\mathrm{OCH}_{3}\right), 54.42(\alpha-\mathrm{C}), 68.03\left(\mathrm{CH}_{2}\right.$ crown $), 68.64\left(\mathrm{CH}_{2}\right.$ crown $)$, $69.36\left(\mathrm{CH}_{2}\right.$ crown), $69.94\left(\mathrm{CH}_{2}\right.$ crown $), 70.44\left(\mathrm{CH}_{2}\right.$ crown $), 70.52\left(\mathrm{CH}_{2}\right.$ crown $), 80.09$ $\left(C\left(\mathrm{CH}_{3}\right)_{3}\right), 98.69$ (C4', C7'), 126.86 (C3, C5), 130.02 (C2, C6), 146.17 (C5', C6'), 155.23 (C2' and $\mathrm{C}=\mathrm{O}$ Boc), 172.08 ( $\mathrm{C}=\mathrm{O}$ ester); UV/Vis (ethanol, $\mathrm{nm}): \lambda_{\max }(\log \varepsilon)=384$ (4.20); MS: $m / z$ (ESI) $586\left([\mathrm{M}+\mathrm{H}]^{+}, 100\right), 586$ (20); HMRS: $m / z$ (ESI) calc. for $\mathrm{C}_{30} \mathrm{H}_{40} \mathrm{~N}_{3} \mathrm{O}_{9}$ 586.27553, found 586.27591.

\subsection{Spectrofluorimetric titrations and chemosensing studies of benzimidazolyl phenylalanine 3}

Solutions of phenylalanine derivative $3\left(c a .1 .0 \times 10^{-5} \mathrm{M}\right)$ and of the cations under study (ca. $1.0 \times 10^{-2} \mathrm{M}$ ) were prepared in UV-grade acetonitrile (in the form of hexahidratated tetrafluorborate salts for $\mathrm{Cu}^{2+}, \mathrm{Co}^{2+}, \mathrm{Ni}^{2+}$ and $\mathrm{Pd}^{2+}$, and perchlorate salts for $\mathrm{Cd}^{2+}, \mathrm{Ca}^{2+}, \mathrm{Na}^{+}$, $\mathrm{Cr}^{3+}, \mathrm{Zn}^{2+}, \mathrm{Hg}^{2+}, \mathrm{Fe}^{2+}$ and $\left.\mathrm{Fe}^{3+}\right)$. Titration of the compound with the several metallic cations was performed by the sequential addition of equivalents of metal cation to the phenylalanine derivative solution, in a $10 \mathrm{~mm}$ path length quartz cuvette and emission spectra were measured by excitation at the wavelength of maximum absorption for compound $\mathbf{3}$. The binding stoichiometry of the phenylalanine derivative with metal cations was determined by Hiperquad Software.

\section{Results and discussion}

\subsection{Synthesis}

Compound $\mathbf{3}$ was synthesized in $70 \%$ yield by condensation of $\mathrm{N}$-t-butyloxycarbonyl-4formyl-L-phenylalanine methyl ester 1 with 4-amino-5-nitrobenzo-15-crown-5-ether 2 in the presence of $\mathrm{Na}_{2} \mathrm{~S}_{2} \mathrm{O}_{4}$ in DMSO at $80{ }^{\circ} \mathrm{C}$ for $15 \mathrm{~h}$ (Scheme 1, Table 1). The synthesized compound was fully characterized by the usual spectroscopic techniques. 
<smiles>CC(=O)OC(=O)NC(Cc1ccc(C=O)cc1)C(=O)O</smiles>

1<smiles>Nc1cc2c(cc1[N+](=O)[O-])OCCOCCOCCOCCO2</smiles>

2

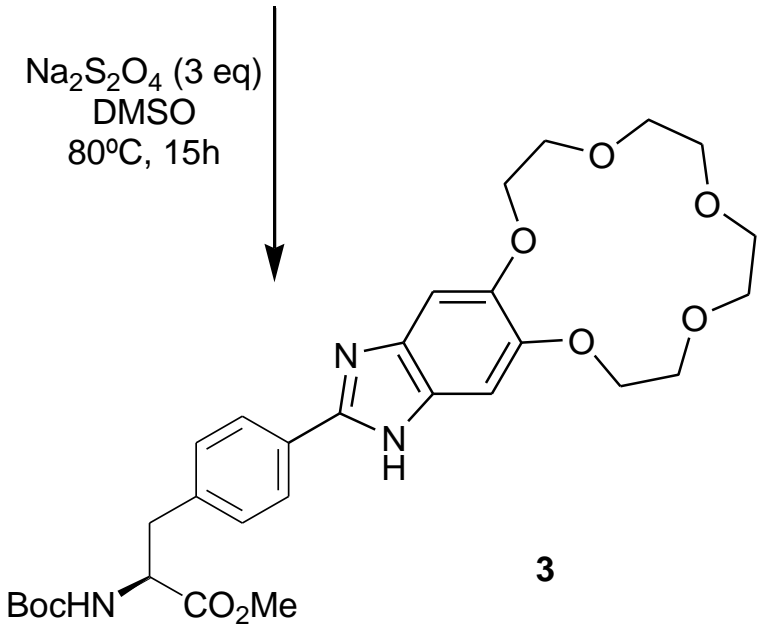

Scheme. Synthesis of benzimidazolyl phenylalanine 3 .

The photophysical properties of compound $\mathbf{3}$ in absolute ethanol were evaluated and the UV/Vis absorption and emission spectra of degassed $10^{-5} \mathrm{M}$ solution were measured (Table 1). Relative fluorescence quantum yield were calculated using 9,10-diphenylanthracene in ethanol as standard $\left(\Phi_{\mathrm{F}}=0.95\right)[5]$.

Table 1. Yield, UV-visible absorption and fluorescence data for benzimidazolyl phenylalanine $\mathbf{3}$, in absolute ethanol.

\begin{tabular}{ccccccc}
\hline & & UV/Vis & \multicolumn{3}{c}{ Fluorescence } \\
\cline { 3 - 7 } Cpd. & Yield & & & Stokes' & $\Phi_{\mathrm{F}}$ \\
& $(\%)$ & $\lambda_{\max }$ & $\log \varepsilon$ & $\lambda_{\text {em }}$ & shift (nm) & \\
\hline $\mathbf{3}$ & 70 & 325 & 4.20 & 384 & 59 & 0.70 \\
\hline
\end{tabular}

\subsection{Spectrofluorimetric titrations of compound 3 with cations in acetonitrile solution}

To explore the sensing ability of compound 3 in solution in the presence of $\mathrm{Ca}^{2+}, \mathrm{Cd}^{2+}, \mathrm{Co}^{2+}$, $\mathrm{Cr}^{3+}, \mathrm{Cu}^{2+}, \mathrm{Fe}^{2+}, \mathrm{Fe}^{3+}, \mathrm{Hg}^{2+}, \mathrm{Na}^{+}, \mathrm{Ni}^{2+}, \mathrm{Pd}^{2+}$ and $\mathrm{Zn}^{2+}$, a preliminary sensing study was performed with addition of 100 equivalents of metal ion to a $100 \mu \mathrm{M}$ acetonitrile solution of 
compound $\mathbf{3}$ (Figures 1 and 2). For all metals, there were no changes in the absorption spectra (ground state) of compound $\mathbf{3}$ but in the emission spectra (excited state) noticeable changes occurerd. So, spectrofluorimetric titrations were performed to understand where and how the interaction with the different metal ions was occurring.
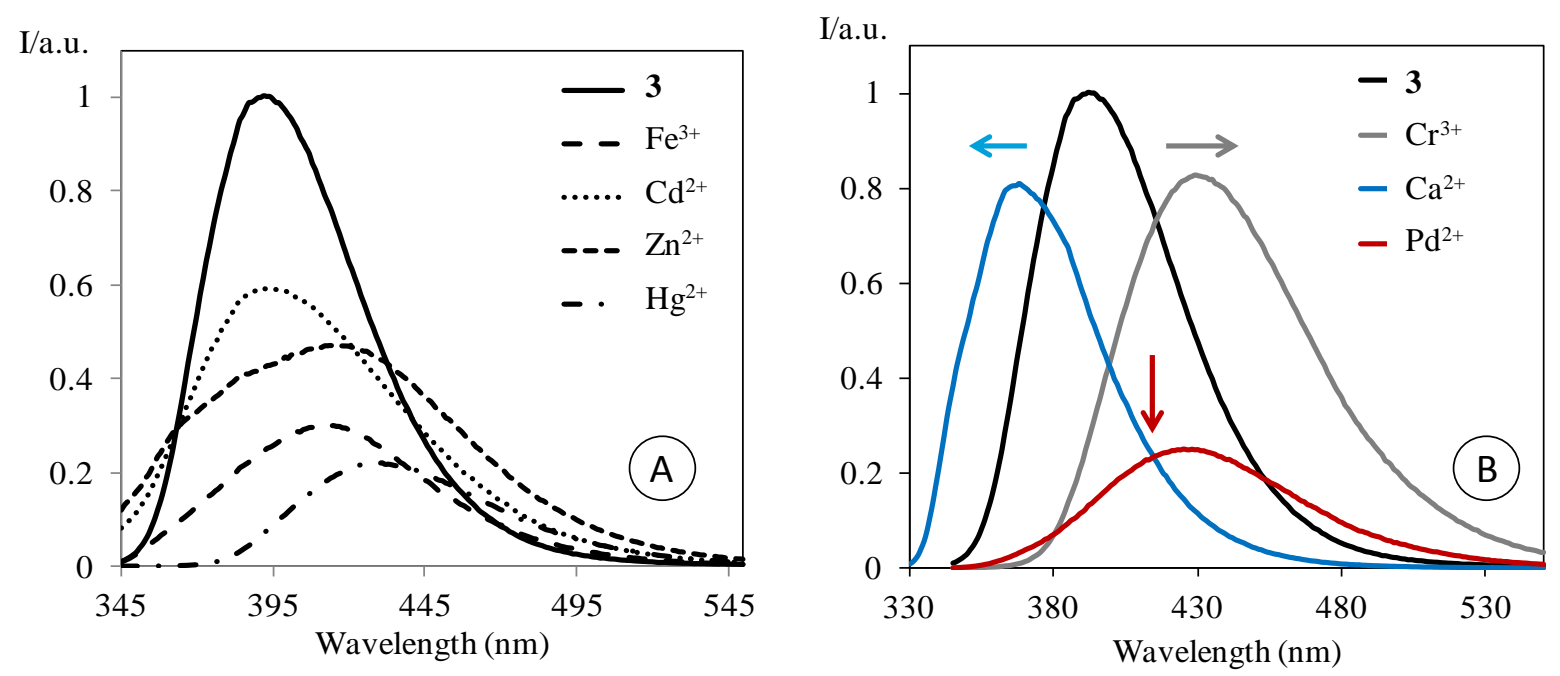

Figure 1. Fluorescence spectra of acetonitrile solutions of compound $\mathbf{3}$ after addition of 100 equivalents of $\mathrm{Fe}^{3+}, \mathrm{Cd}^{2+}, \mathrm{Zn}^{2+}$ and $\mathrm{Hg}^{2+}(\mathrm{A})$, and $\mathrm{Cr}^{3+}, \mathrm{Ca}^{2+}$ and $\mathrm{Pd}^{2+}(\mathrm{B})$.

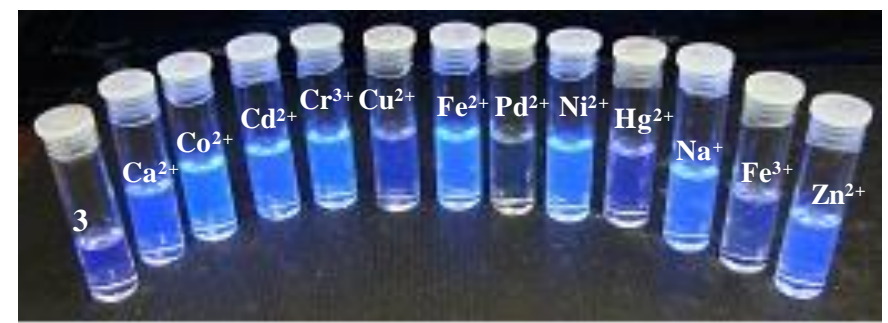

Figure 2. Emission under irradiation at $365 \mathrm{~nm}$ of some ethanolinc solutions of compound 3 in the presence of 100 equivalents of several cations.

The stronger interaction was observed in the presence of $\mathrm{Pd}^{2+}$ and $\mathrm{Cu}^{2+}$ where only 1.6 and 3.0 equivalents are enough to quench the emission, respectively (see Figures 3 and 4). A CHEQ (chelation enhancement of the quenching) effect in the fluorescence emission for both metals was observed. In the case of $\mathrm{Zn}^{2+}, \mathrm{Cr}^{3+}, \mathrm{Cd}^{2+}, \mathrm{Co}^{2+}, \mathrm{Hg}^{2+}, \mathrm{Ni}^{2+}$ and $\mathrm{Fe}^{2+}$, that normally produce a CHEF effect (chelation enhancement of fluorescence), a 40\% till 70\% quenching effect was also observed. Moreover, a large red shift (30 to $45 \mathrm{~nm}$ ) in the emission band was 
observed for several metals. In some cases, a new red-shifted band appeared, whereas a different behavior (a blue shift) was observed when $\mathrm{Ca}^{2+}$ and $\mathrm{Na}^{+}$were added (Figure 1).

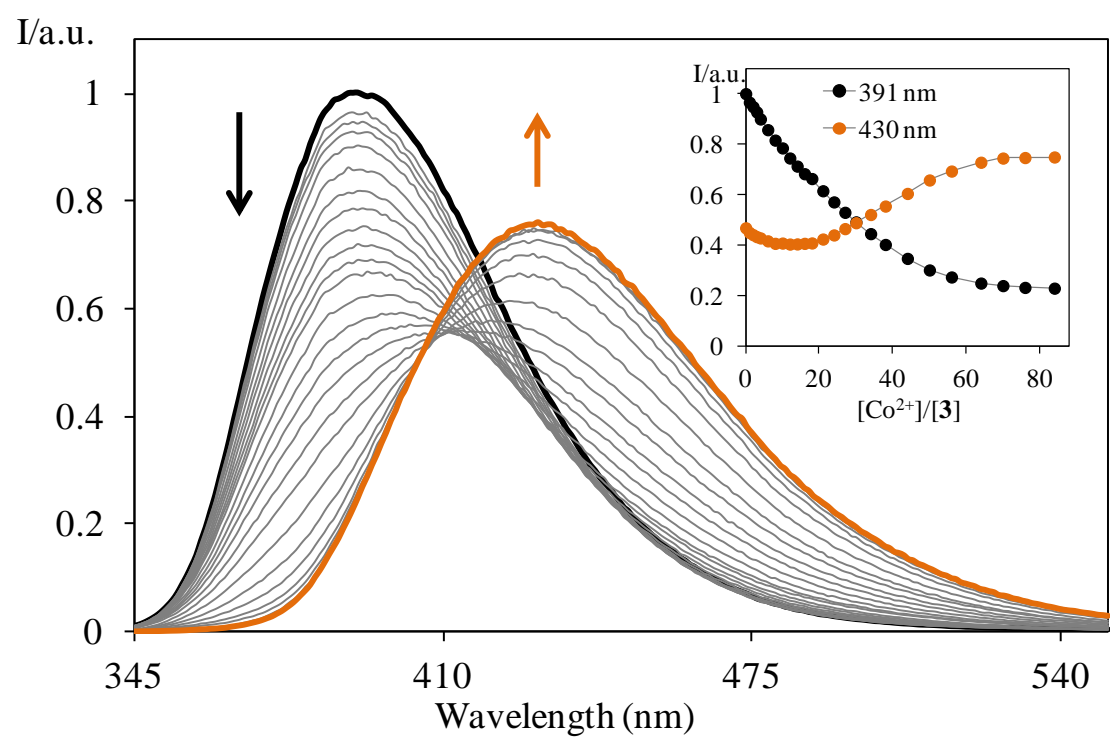

Figure 3. Spectrofluorimetric titrations of compound $\mathbf{3}$ in the presence of $\mathrm{Co}^{2+}$, in acetonitrile solution. ([3] $\left.=10 \mu \mathrm{M}, \mathrm{T}=298 \mathrm{~K}, \lambda_{\mathrm{exc}} \mathbf{3}=325 \mathrm{~nm}\right)$. Inset: normalised emission at $391 \mathrm{~nm}$ and $430 \mathrm{~nm}$ as a function of added metal equivalents.

With the addition of $\mathrm{Co}^{2+}$, compound $\mathbf{3}$ showed a small red shift on the fluorescence emission spectra and a new band enhanced at $\sim 430 \mathrm{~nm}$ (Figure 2). The emission spectra showed the formation of a well-defined isoemissive point at $416 \mathrm{~nm}$. These results suggest the existence of two or more species in solution, and also that the interaction is taking place between the metal ion and the nitrogen of the imidazo moiety. The complexation constant fits to a mononuclear species for compound 3 with value of $\log \beta 3.571 \pm 0.011$.

The more efficient interaction was between compound $\mathbf{3}$ and $\mathrm{Pd}^{2+}$, which only required 1.6 equivalents to quench almost $80 \%$ of the initial fluorescence. However, the best result was obtained for $\mathrm{Cu}^{2+}$ with a complete quenching of the fluorescence emission, reaching a plateau at 3.0 equivalents of metal ion. The mononuclear species was formed with complexation constants with values of $\log \beta 5.188 \pm 0.025$ and $\log \beta 7.800 \pm 0.012$ for $\mathrm{Pd}^{2+}$ and $\mathrm{Cu}^{2+}$, respectively. 


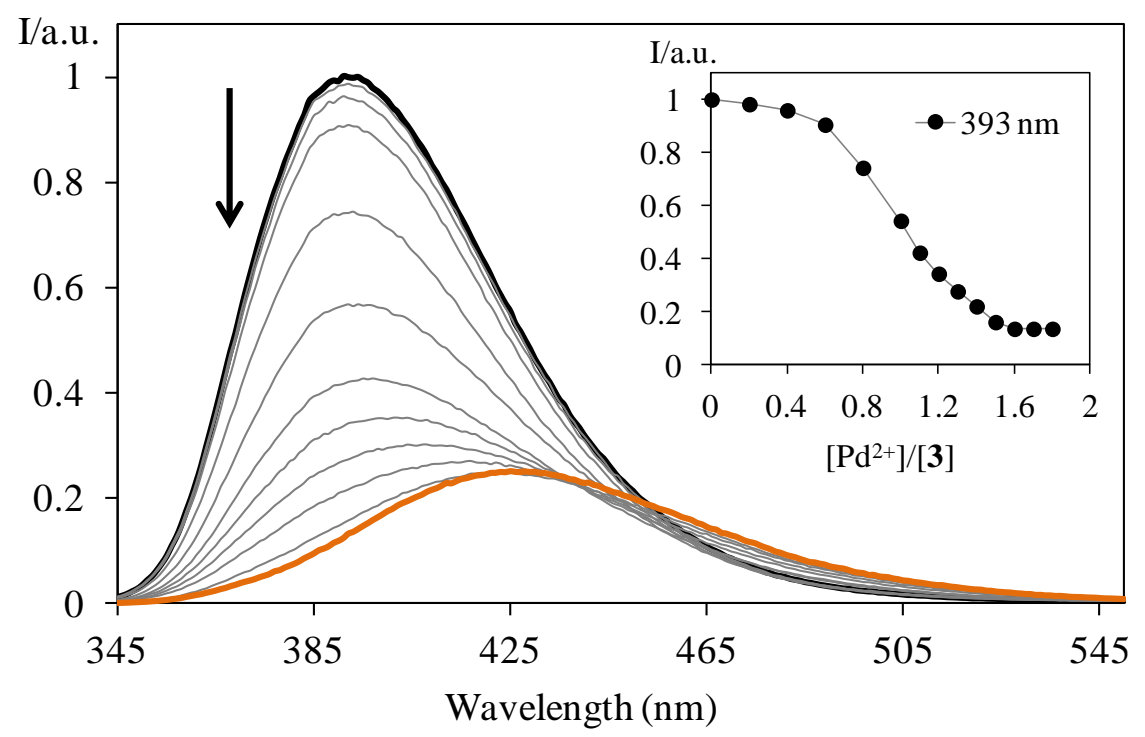

Figure 4. Spectrofluorimetric titrations of compound $\mathbf{3}$ in the presence of $\mathrm{Pd}^{2+}$, in acetonitrile solution. ([3] $\left.=10 \mu \mathrm{M}, \mathrm{T}=298 \mathrm{~K}, \lambda_{\mathrm{exc}} \mathbf{3}=325 \mathrm{~nm}\right)$. Inset: normalised emission at $393 \mathrm{~nm}$ as a function of added metal equivalents.

\section{Conclusions}

Compound 3 was synthesized in excellent yield (70\%) using a simple experimental procedure. The sensory ability was evaluated for several metal ions by spectrofluorimetric titrations in acetonitrile, and it was found that benzimidazolyl-phenylalanine $\mathbf{3}$ was a suitable chemosensor for $\mathrm{Hg}^{2+}, \mathrm{Cu}^{2+}$ and $\mathrm{Pd}^{2+}$ showing higher sensitivity for these cations when compared to $\mathrm{Co}^{2+}, \mathrm{Cr}^{3+}, \mathrm{Fe}^{3+}, \mathrm{Ni}^{2+}, \mathrm{Zn}^{2+}$ and $\mathrm{Cd}^{2+}$, as an almost complete fluorescence quenching was achieved with the addition of 1.6 and 3.0 metal equivalents, respectively.

\section{Acknowledgements}

Thanks are due to Fundação para a Ciência e Tecnologia (Portugal) for financial support to the Portuguese NMR network (PTNMR, Bruker Avance III 400-Univ. Minho), FCT and FEDER (European Fund for Regional Development)-COMPETEQREN-EU for financial support to the research centre CQ/UM [PEst-C/QUI/UI0686/2011 (FCOMP-01-0124FEDER-022716)] and a post-doctoral grant to R.M.F. Batista (SFRH/BPD/79333/2011).

\section{References}

[1] (a) Martínez-Manêz, R.; Sancenón, F. Coord. Chem. Rev. 250 (2006) 3081-3093. (b) Kaur, N.; Kumar, S. Tetrahedron 67 (2011) 9233-9264. (c) Liu, Z.; He, W.; Guo, Z. Chem. Soc. Rev. 42 (2013) 1568-600. 
[2] (a) Taylor, P.; Zhu, L.; Zhang, L.; Younes, A. H. Supramol. Chem. (2011), 37-41. (b) Alfonso, M.; Sola, A.; Caballero, A.; Tárraga, A.; Molina, P. Dalton trans. (2009) 96539658.

[3] (a) Tsukanov, A. V; Dubonosov, A. D.; Bren, V. A.; Minkin, V. I. Chem. Heterocycl. Compd. 44 (2008) 899-923.

[4] (a) Batista, R. M. F.; Oliveira, E.; Costa, S. P. G.; Lodeiro, C.; Raposo, M. M. M. Org. Lett. 9 (2007) 3201-3204; (b) Batista, R. M. F.; Oliveira, E.; Costa, S. P. G.; Lodeiro, C.; Raposo, M. M. M. Talanta 85 (2011) 2470-2478; (c) Batista, R. M. F.; Oliveira, E.; Costa, S. P. G.; Lodeiro, C.; Raposo, M. M. M. Tetrahedron 67 (2011) 7106-7113; (d) Batista, R. M. F.; Ferreira, R. C. M.; Raposo, M. M. M.; Costa, S. P. G. Tetrahedron 68 (2012) $7322-$ 7330; (e) Batista, R. M. F.; Costa, S. P. G.; Raposo, M. M. M. J. Photochem. Photobiol. A 259 (2013) 33-40; (f) Batista, R. M. F.; Oliveira, E.; Costa, S. P. G.; Lodeiro, C.; Raposo, M. M. M. Supramol. Chem. (2013) DOI: 10.1080/10610278.2013.824082.

[5] Morris, J. V.; Mahaney, M. A.; Huber, J. R. J. Phys. Chem. 80 (1976) 969-974. 